\title{
Clinical Value of Serum Neopterin in Breast Cancer
}

\author{
Suzy F. Gohar ${ }^{1}$, Suzan A. Al-Hassanin ${ }^{1}$, Amira M. Shehata ${ }^{2}$, Shaimaa S. Soliman ${ }^{3}$ \\ ${ }^{1}$ Clinical Oncology Department, Faculty of Medicine, Menoufia University, Shebin Elkom, Egypt; \\ ${ }^{2}$ Clinical Pathology Department, Faculty of Medicine, Menoufia University, Shebin Elkom, Egypt; \\ ${ }^{3}$ Public Health and Community Medicine Department, Faculty of Medicine, Menoufia University, \\ Shebin Elkom, Egypt
}

Background: The immune marker neopterin may have a prognostic role in different cancers including breast cancer. Aim: To assess the relation between pre-chemotherapy serum level of neopterin and the clinical and pathological features of breast cancer patients.

Methods: Sixty-three patients with histologically confirmed breast cancer and 20 healthy females matched for age and sex as controls were included. All patients were subjected to full history taking, thorough medical examination and complete investigation. Venous blood samples were collected from all participants to measure serum neopterin level. Serum neopterin level more than $10 \mathrm{nMol} \backslash \mathrm{L}$ was considered elevated.

Results: The mean serum neopterin level among patients was $8 \pm 7.43$. Twenty-two patients (34.9\%) had elevated serum neopterin level. Neopterin was found to be significantly elevated in patients with advanced stages and grade III tumors. Metastatic disease was associated with significantly higher levels of neopterin $(p=0.04)$. There was no significant association between high neopterin level and mean time to progression or overall survival.

Conclusion: Among breast cancer patients, the immune marker neopterin was significantly related to metastatic disease and it could be considered a potential marker for systemic spread of the tumor.

Keywords: Breast cancer, Metastatic disease, Prognosis, Neopterin.

Corresponding author: Dr. Suzy Gohar; Faculty of Medicine, Menoufia University, Shebin Elkom, 32511, Egypt; Email: suzygohar@ymail.com

Submitted: 15-June-2018, Revised: 23-July-2018, Accepted: 4-August-2018, Published online: 2-October-2018

\section{INTRODUCTION}

The aromatic pteridine neopterin is produced by monocytes and macrophages in response to the stimulatory effect of interferon-gamma (IFN- $\gamma$ ) that is secreted by activated $\mathrm{T}$-cells. Its production reflects the activity of monocytes and macrophages and may provide information about the status of cellular immunity, so neopterin acts as a marker for immune system activation. Increased neopterin concentration in various body fluids has been observed in patients with viral infection or an autoimmune disease and in patients experiencing allograft rejection ${ }^{1}$.

Increased urinary and serum neopterin concentrations have been reported in a variety of cancers including ovarian, cervical, endometrial and vulvar carcinomas and uterine sarcomas ${ }^{2}$. A significant positive correlation was found between higher neopterin levels and advanced tumor stage. In addition, high neopterin levels were associated significantly with poor prognosis 3.

The aim of the current study was to determine the relation between serum neopterin level and the clinicopathological features of breast cancer and to explore its role as a potential prognostic marker for systemic tumor spread.

\section{METHODS}

\section{Patients}

Sixty-three histologically confirmed breast cancer patients presented at the Clinical Oncology Department, Faculty of Medicine, Menoufia University, Egypt, were enrolled in this prospective study between March 2016 and October 2016.

Patients with personal history of other cancer types or who had previously received chemotherapy were excluded. Twenty age and sex matched females were included as control group.

After approval of the ethical committee, all participants were subjected to full history taking, thorough medical examination and investigations including: complete blood count, baseline kidney and liver function tests, chest X-ray and abdominal and pelvic ultrasound for patients with early stage disease. Computed tomography scan of chest, abdomen and pelvis, bone scan and baseline tumor markers (carbohydrate antigen 15-3 and carcino-embryonic antigen) were done for patients with advanced stage disease.

Patients were staged according to the American Joint Committee on Cancer (AJCC) staging system and performance status was graded according to the Eastern Cooperative Oncology Group (ECOG) performance status scale. 
All participants signed an informed consent to provide a blood sample and to review the medical record for research purposes.

\section{Analytical procedures}

Venous blood samples were obtained by sterile venipuncture before the start of chemotherapy for patients and controls and was divided into 2 parts. The $1^{\text {st }}$ part was transferred into di-potassium ethylene diamine tetra-acetic acid (EDTA) vacutainer tube for peripheral blood cell count. The $2^{\text {nd }}$ part was transferred into plain vacutainer tube, left to clot at room temperature, then centrifuged at a speed of $3000 \mathrm{rpm}$ for $10 \mathrm{~min}$. Separated serum for estimation of neopterin level was kept frozen at $-20{ }^{\circ} \mathrm{c}$ until analysis.

Serum neopterin was analyzed by specific enzymelinked immunosorbent assay (ELISA) kit (IBL International GMBH, Hamburg, Germany) according to the manufacturer's instructions. Neopterin level above 10 nanomole/liter (nmol/L) was considered elevated.

Peripheral blood cell count was performed immediately using Sysmex XN-10 blood analyzer (Sysmex, Kobe, Japan).

\section{Statistical analysis}

Data was collected, tabulated and analyzed by an IBM compatible personal computer using SPSS statistical package version 23 (IBM SPSS statistics for windows, version 23.0, Armnok, NY: IBM Corp.). Student's $t$-test is a test of significance used to compare the quantitative variables between two groups of normally distributed data, while Mann Whitney's test was used to compare the quantitative variables between two groups with abnormal data distribution. For comparison of quantitative variables between more than two consecutive measures in the same group of abnormally distributed data Friedman test was used. Wilcoxon test was conducted to compare different readings of abnormally distributed data in the same group.

\section{RESULTS}

The mean age of the patients was $50.55 \pm 12.07$ and $33(52.4 \%)$ patients were less than 50 years old. Most patients were postmenopausal and had good performance status. Twelve patients did not undergo breast surgery due to either locally advanced disease or presence of metastases. The most common pathological subtype was invasive duct carcinoma and the majority had stage III disease at diagnosis. HER-2/neu positive disease represented $38.1 \%$ of the patients. Single metastatic site was seen in $14.3 \%$ of patients with visceral involvement. Most of the patients finished their adjuvant treatment schedule with minimum treatment related complications (table 1).

Pre-chemotherapy mean serum neopterin levels in patients and controls were $8 \pm 7.43$ and $6.09 \pm 3.98$ respectively without statistically significant difference $(\mathrm{p}=0.54)$. While the median values for patients and controls were $7.2 \mathrm{nmol} / \mathrm{L}$ (range $0-35 \mathrm{nmol} / \mathrm{L}$ ) and 5.4 nmol/L (range 0-12 nmol/L) respectively.
Table 1: Patients' and disease characteristics

\begin{tabular}{|c|c|c|}
\hline & $\begin{array}{l}\text { No } \\
\text { (total =63) }\end{array}$ & $\%$ \\
\hline \multicolumn{3}{|l|}{ Age } \\
\hline$\leq 50 \mathrm{y}$ & 33 & 52.4 \\
\hline$>50 \mathrm{y}$ & 30 & 47.6 \\
\hline \multicolumn{3}{|l|}{ Menopausal status } \\
\hline Premnopausal & 38 & 60.3 \\
\hline Postmenopausal & 25 & 39.7 \\
\hline \multicolumn{3}{|l|}{ ECOG performance status } \\
\hline 0 & 41 & 65.1 \\
\hline 1 & 18 & 28.6 \\
\hline 2 & 4 & 6.3 \\
\hline \multicolumn{3}{|l|}{ Surgery } \\
\hline None & 12 & 19 \\
\hline Conservative sugery & 4 & 6.3 \\
\hline Modified radical mastectomy & 43 & 68.3 \\
\hline \multicolumn{3}{|l|}{ Pathology } \\
\hline Infiltrating duct carcinoma & 59 & 93.7 \\
\hline Infiltrating lobular carcinoma & 3 & 4.8 \\
\hline \multicolumn{3}{|l|}{ Size } \\
\hline $\mathrm{T} 1$ & 6 & 9.5 \\
\hline $\mathrm{T} 2$ & 32 & 50.8 \\
\hline $\mathrm{T} 3$ & 19 & 30.2 \\
\hline $\mathrm{T} 4$ & 6 & 9.5 \\
\hline \multicolumn{3}{|l|}{ Nodal status } \\
\hline No & 10 & 15.9 \\
\hline N1 & 5 & 7.9 \\
\hline $\mathrm{N} 2$ & 10 & 15.9 \\
\hline N3 & 23 & 36.5 \\
\hline $\mathrm{Nx}$ & 12 & 19 \\
\hline \multicolumn{3}{|l|}{ Stage } \\
\hline $\mathrm{I}$ & 7 & 11.1 \\
\hline II & 9 & 14.3 \\
\hline III & 35 & 55.6 \\
\hline IV & 12 & 19 \\
\hline \multicolumn{3}{|l|}{ Grade } \\
\hline $\mathrm{I}$ & 1 & 1.6 \\
\hline II & 56 & 88.9 \\
\hline III & 6 & 9.5 \\
\hline \multicolumn{3}{|l|}{ HER-2/neu } \\
\hline Positive & 24 & 38.1 \\
\hline Negative & 39 & 61.9 \\
\hline \multicolumn{3}{|l|}{ Number of metastases } \\
\hline 0 & 49 & 81 \\
\hline 1 & 9 & 14.3 \\
\hline 2 & 3 & 4.8 \\
\hline \multicolumn{3}{|l|}{ Site of metastases } \\
\hline Visceral & 6 & 89.5 \\
\hline Bone & 4 & 6.3 \\
\hline Visceral and bone & 2 & 3.2 \\
\hline
\end{tabular}


A significant positive correlation was found between neopterin level and total leucocytic count (TLC) and absolute neutrophil and lymphocytic counts. However; a negative correlation was observed between serum neopterin level and both neutrophil/lymphocyte ratio and hemoglobin level (table 2).

Table 2: Correlation between complete blood count measurements and neopterin level

\begin{tabular}{llll}
\hline Items & $\begin{array}{l}\text { All patients } \\
(\mathbf{n}=63), \text { Mean } \pm\end{array}$ & \multicolumn{2}{l}{ Neopterin } \\
\cline { 3 - 4 } & SD & $\boldsymbol{r}$ & $\begin{array}{l}\mathbf{p} \\
\text { value }\end{array}$ \\
\hline $\begin{array}{l}\text { Total leukocytic } \\
\text { count }\end{array}$ & $7.24 \pm 3.13$ & 0.38 & 0.002 \\
\hline Neutrophils & $4.10 \pm 2.40$ & 0.25 & 0.04 \\
\hline lymphocytes & $2.14 \pm 1.09$ & 0.33 & 0.007 \\
\hline Monocytes & $0.55 \pm 0.23$ & 0.17 & 0.16 \\
\hline N/L ratio & $2.05 \pm 1.06$ & -0.001 & 0.99 \\
\hline Hemoglobin & $11.6 \pm 1.26$ & -0.24 & 0.04 \\
\hline Platelets & $292.8 \pm 79.91$ & 0.15 & 0.21 \\
\hline
\end{tabular}

There was no significant correlation between body mass index and serum neopterin level $(\mathrm{r}=0.14, \mathrm{p}=$ 0.025). Mean serum neopterin level was higher in postmenopausal patients above 50 years old. In relation to disease features mean serum neopterin was higher in patients with infiltrating duct carcinoma pathology, T3 and 4, node positive, stage III and IV, higher tumor grade and HER-2/neu positive tumors. Metastasis was significantly associated with higher levels of neoptrin; as patients with metastases had significantly higher levels of neoptrin than non-metastatic patients (table 3 ).

Thirty-five percent of patients had high neopterin level with the following characteristics: $>50$ years old, infiltrating duct carcinoma pathology, T3 and T4 tumors, N3 disease, grade III tumors and visceral and bone involvement. Elevated serum neopterin level was significantly more prevalent among metastatic patients $(\mathrm{p}=0.01)($ Table 4).

The mean overall time to progression was 28.5 months (95\% Confidence Interval [CI]: 27.08 - 29.91), with no significant difference between patients with low neoptrin (28.19 months, 95\% CI: 26.22 - 30.16) and those with high neoptrin (29.09 months, 95\% CI: 27.35 30.83). The same was observed in the overall survival time which was 28.8 months (95\% CI: 27.62 - 29.97), with no siginicant difference between patients with low neoptrin (28.57 months, 95\% CI: 26.95 - 30.18) and those with high neoptrin (29.22 months, 95\% CI: 27.74 30.7). The median survival was not reached in both groups.

\section{DISCUSSION}

Neopterin is a molecule that contains pteridine ring in body fluids and tissues. Urinary neopterin level is increased in patients with malignancy and viral infection ${ }^{4}$. It is an indicator of the immune system activation in case of malignancy ${ }^{1}$.
Among our group of patients, the mean serum neopterin level was $8 \pm 7.43$ without statistically significant difference between patients and controls. This

Table 3: The relation between mean serum neopterin levels and patients \& disease characteristics.

\begin{tabular}{|c|c|c|c|}
\hline & $\begin{array}{l}\text { Neopterin } \\
\text { Mean } \pm \text { SD }\end{array}$ & Test & $\begin{array}{l}\mathrm{P} \\
\text { value }\end{array}$ \\
\hline \multicolumn{4}{|l|}{ Age } \\
\hline$\leq 50$ & $7.98 \pm 6.75$ & \multirow[t]{2}{*}{$\mathrm{U}=0.26$} & \multirow[t]{2}{*}{0.78} \\
\hline$>50$ & $8.01 \pm 8.24$ & & \\
\hline \multicolumn{4}{|l|}{ Menopausal status } \\
\hline Premenopausal & $7.62 \pm 6.83$ & \multirow[t]{2}{*}{$\mathrm{U}=0.38$} & \multirow[t]{2}{*}{0.7} \\
\hline Postmenopausal & $8.57 \pm 8.39$ & & \\
\hline \multicolumn{4}{|l|}{$\begin{array}{l}\text { ECOG Performance } \\
\text { Status }\end{array}$} \\
\hline 0 & $6.81 \pm 6.38$ & \multirow[t]{3}{*}{$K=2.62$} & \multirow[t]{3}{*}{0.26} \\
\hline 1 & $9.84 \pm 7.17$ & & \\
\hline 2 & $11.9 \pm 15.74$ & & \\
\hline \multicolumn{4}{|l|}{ Pathology } \\
\hline $\begin{array}{l}\text { Infiltrating duct } \\
\text { carcinoma }\end{array}$ & $7.91 \pm 7.45$ & \multirow[t]{2}{*}{$\mathrm{U}=1.06$} & \multirow[t]{2}{*}{0.28} \\
\hline $\begin{array}{l}\text { Infiltrating lobular } \\
\text { carcinoma }\end{array}$ & $3.9 \pm 5.74$ & & \\
\hline \multicolumn{4}{|l|}{ Size } \\
\hline $\mathrm{T} 1,2$ & $6.62 \pm 6.06$ & \multirow[t]{2}{*}{$\mathrm{U}=1.43$} & \multirow[t]{2}{*}{0.15} \\
\hline $\mathrm{T} 3,4$ & $10.09 \pm 8.87$ & & \\
\hline \multicolumn{4}{|l|}{ Nodal status } \\
\hline Negative & $6.28 \pm 5.77$ & \multirow[t]{2}{*}{$\mathrm{U}=0.52$} & \multirow[t]{2}{*}{0.59} \\
\hline Positive & $8.02 \pm 6.87$ & & \\
\hline \multicolumn{4}{|l|}{ Stage } \\
\hline I & $4.81 \pm 5.86$ & \multirow[t]{4}{*}{$K=4.79$} & \multirow[t]{4}{*}{0.18} \\
\hline II & $7.75 \pm 4.42$ & & \\
\hline III & $6.76 \pm 5.65$ & & \\
\hline IV & $14.44 \pm 11.69$ & & \\
\hline \multicolumn{4}{|l|}{ Grade } \\
\hline I, II & $7.77 \pm 7.7$ & \multirow[t]{2}{*}{$\mathrm{U}=1.14$} & \multirow[t]{2}{*}{0.25} \\
\hline III & $9.56 \pm 5.15$ & & \\
\hline \multicolumn{4}{|l|}{ HER-2/neu } \\
\hline Negative & $7.86 \pm 7.12$ & \multirow[t]{2}{*}{$\mathrm{U}=0.03$} & \multirow[t]{2}{*}{0.97} \\
\hline Positive & $8.08 \pm 7.71$ & & \\
\hline
\end{tabular}

\begin{tabular}{llll}
\hline $\begin{array}{l}\text { Presence of } \\
\text { metastases }\end{array}$ & & & \\
\cline { 1 - 2 } Yes & $6.56 \pm 5.45$ & $\mathrm{U}=2.04$ & 0.04 \\
\cline { 1 - 2 } No & $14.11 \pm 11.21$ & & \\
\cline { 1 - 2 } Site of metastases & & & \\
\cline { 1 - 2 } Visceral & $12 \pm 12.87$ & & \\
\cline { 1 - 2 } Bone & $11.1 \pm 7.29$ & & 0.22 \\
\cline { 1 - 2 } Visceral and bone & $26.5 \pm 4.94$ & & \\
\cline { 1 - 2 } Hormonal status & & & \\
\cline { 1 - 2 } Negative & $8.7 \pm 6.66$ & & \\
\cline { 1 - 2 } Positive & $7.71 \pm 7.77$ & & \\
\hline
\end{tabular}

ECOG: Eastern Cooperative Oncology Group 
Table 4: Features of patients with high serum neopterin level

\begin{tabular}{|c|c|c|}
\hline & $\begin{array}{l}\text { No. }(\%), \\
\text { total }=22\end{array}$ & $\begin{array}{l}\mathbf{p} \\
\text { value }\end{array}$ \\
\hline \multicolumn{3}{|l|}{ Age (years) } \\
\hline$\leq 50$ & $12(54.5)$ & \multirow[t]{2}{*}{0.63} \\
\hline$>50$ & $10(45.5)$ & \\
\hline \multicolumn{3}{|l|}{ Menopausal status } \\
\hline Premenopausal & $13(59.1)$ & \multirow[t]{2}{*}{0.88} \\
\hline Postmenopausal & $9(40.9)$ & \\
\hline \multicolumn{3}{|l|}{ ECOG performance status } \\
\hline 0 & $12(54.5)$ & \multirow[t]{3}{*}{0.27} \\
\hline 1 & $9(40.9)$ & \\
\hline 2 & $1(4.5)$ & \\
\hline \multicolumn{3}{|l|}{ Surgery } \\
\hline None & $3(13.6)$ & \multirow[t]{3}{*}{0.49} \\
\hline Conservative surgery & $1(4.5)$ & \\
\hline Modified radical mastectomy & $18(81.8)$ & \\
\hline \multicolumn{3}{|l|}{ Pathology } \\
\hline Infiltrating duct carcinoma & $21(95.4)$ & \multirow[t]{2}{*}{1} \\
\hline Infiltrating lobular carcinoma & $1(4.8)$ & \\
\hline \multicolumn{3}{|l|}{ Stage } \\
\hline I & $2(9.1)$ & \multirow[t]{4}{*}{0.19} \\
\hline II & $3(13.6)$ & \\
\hline III & $10(45.5)$ & \\
\hline IV & $7(31.8)$ & \\
\hline \multicolumn{3}{|l|}{ Grade } \\
\hline I & 0 & \multirow[t]{3}{*}{0.07} \\
\hline II & $17(77.3)$ & \\
\hline III & $5(22.7)$ & \\
\hline \multicolumn{3}{|l|}{ Distant metastases } \\
\hline No & $14(63.6)$ & \multirow[t]{2}{*}{0.01} \\
\hline Yes & $8(36.4)$ & \\
\hline \multicolumn{3}{|l|}{ Site of metastases (8 pts) } \\
\hline Visceral & $4(50)$ & \multirow[t]{3}{*}{0.75} \\
\hline Bone & $2(25)$ & \\
\hline Visceral and bone & $2(25)$ & \\
\hline \multicolumn{3}{|l|}{ Hormonal status } \\
\hline Negative & $8(22.2)$ & \multirow[t]{2}{*}{0.31} \\
\hline Positive & $14(63.6)$ & \\
\hline
\end{tabular}

ECOG: Eastern Cooperative Oncology Group

agrees with Kocer et al ${ }^{5}$ and disagrees with Yildirim et al ${ }^{1}$ who found a significant difference between cases and controls regarding serum neopterin readings.

In this work, neopterin was positively correlated to baseline TLC, absolute neutrophilic and lymphocytic counts indicating that neopterin was associated with activation of white blood cells precursors in the bone marrow.

Neopterin's negative correlation to hemoglobin points to the role of the immune system in the anemia of chronic disease by affecting hemoglobin metabolism.
The negative relation between urinary neopterin level and hemoglobin was confirmed by Melichar et al who related serum neopterin level to chemotherapy induced anemia in patients with breast cancer receiving chemotherapy ${ }^{6}$.

Serum neopterin levels were higher among patients with T4 and node positive disease indicating that its level is correlated with tumor burden. This finding is different from that of Yildirim et al who found no relation between serum neopterin and tumor burden ${ }^{1}$. In our study the mean serum neopterin was higher in patients with HER-2/neu over expression which is again correlated to aggressive disease.

On comparing serum neopterin level in different disease stages, our results showed that advanced stage disease had higher mean serum neopterin than earlier stage without significant difference. On the contrary, Yildirim et al reported a significant difference in the mean serum neopterin levels between early nonmetastatic disease and metastatic disease ${ }^{1}$. Demian et al found that neopterin level was positively correlated with tumor stage and the presence of metastasis and concluded that it can be a valuable marker for the immune status of patients and presence of metastases ${ }^{7}$.

Another important observation in our study is that serum neopterin levels were significantly higher in patients with two or more metastatic sites and among patients with both bone and liver involvement which is in agreement with Yildirim et al ${ }^{1}$. This could be explained by the persistent stimulation of the immune system in case of continuous tumor growth translated in the form of elevated serum neopterin.

Subgroup analysis of the 22 patients with high neopterin level above the cutoff value was done. They represented about $35 \%$ of our cases which is higher than the percentage reported by Kocer et al who found that only $14(25 \%)$ patients out of 56 patients had pretreatment elevated serum neopterin levels ${ }^{5}$. In such group of patients, high serum neopterin levels did not show any significant correlation with age, body mass index, menopausal status or performance status, while a significant correlation with age was found in the study of Kocer et al ${ }^{5}$. The only significant factor was the presence of metastases.

Although we didn't confirm a relation between serum neopterin and the type of surgery, an elevated serum neopterin was noticed among patients who underwent modified radical mastectomy rather than others which indicates that surgery itself did not affect immune system activation related to the malignant tumor.

High neopterin level was more prevalent in patients with advanced stage and in both visceral and bone involvement but this difference was not statistically significant. This did not match with the findings of Kocer et al who reported that high serum neopterin was significantly related with advanced stage and metastatic disease $^{5}$.

\section{Conclusion}

Serum neopterin level was significantly correlated with baseline TLC and absolute neutrophil and 
lymphocytic counts, but negatively correlated with hemoglobin. The prevalence of high neopterin level among patients was $34.9 \%$ and it was significantly related to metastatic disease indicating that neopterin could be considered as an indicator of disease burden in this group of patients. More time is needed to evaluate the prognostic effect of serum neopterin on survival in our group of breast cancer patients.

\section{REFERENCES}

1- Yildirim Y, Gunel N, Coskun U, Pasaoglu H, Aslan $\mathrm{S}$, Cetin A. Serum neopterin levels in patients with breast cancer. Med Oncol. 2008; 25(4): 403-407.

2- Melichar B, Spisarová1 M, Bartoušková1 M, Krčmová L, Javorská L, Študentová H. Neopterin as a biomarker of immune response in cancer patients. Ann Transl Med. 2017; 5(13): 280

3- Sucher R, Schroecksnadel K, Weiss G, Margreiter R, Fuchs D, Brandacher G. Neopterin, a prognostic marker in human malignancies. Cancer Lett. 2010; 287(1): 13-22.

4- Akgul E, Aydın I, Caycı T, Kurt Y, Aydın F, Agıllı M. The indicator of cellular immune response in body fluids: Neopterin. Gülhane Tip Derg. 2013; 55(3): 237-243.

5- Kocer B, Turan U, Surmeli S, et al. Serum neopterin as a prognostic indicator in patients with breast carcinoma. Cent Eur J Med. 2010; 5(5): 544-550.

6- Melichar B, Urbánek L, Krčmová L, et al. Urinary neopterin, hemoglobin and peripheral blood cell counts in breast carcinoma patients treated with dose-dense chemotherapy. Anticancer Res. 2008; 28(4C): 2389-2396.

7- Demian SR, El-Sayed MH, El-Sedfy AS, Ahmed AS, Ahmedai FM. The role of neopterin in patients with primary and metastatic breast cancer: correlation with clinicopathological data. J Immunother Cancer. 2014; 2(Suppl 3): P147. 